\title{
Differences in viability and reactivity of actinospores of three myxozoan species upon ageing
}

\author{
Dennis Marc Kallert and Mansour El-Matbouli \\ Clinic for Fish and Reptiles, Faculty of Veterinary Medicine, University of Munich, Kaulbachstraße 37, D-80539 Munich, \\ Germany
}

Key words: Myxozoa, Myxobolus cerebralis, Myxobolus pseudodispar, Henneguya nuesslini, viability, polar capsule discharge, actinospore, temperature, age, fluorescent staining

\begin{abstract}
Little is known about the viability of myxozoan actinospore stages after harvest from laboratory cultures of infected oligochaete worms. The viability and reactivity of actinospores of three myxozoan species was evaluated after short-term storage at $4{ }^{\circ} \mathrm{C}$ and $12^{\circ} \mathrm{C}$. Two methods of determining actinospore viability were compared: differential fluorescent staining and direct microscopic observation of morphological indicators of spore integrity. Spore reactivity was quantified by measuring polar filament discharge rates in a micro-assay with fish mucus substrate and mechanical stimulation by vibration. The age-dependent viability of the three species showed clear differences. Myxobolus cerebralis actinospores had the shortest effective life span whereas Henneguya nuesslini actinospores survived significantly longer. Storage at lower temperatures yielded higher viability in all species. Myxobolus pseudodispar actinospores were significantly robust up to $12^{\circ} \mathrm{C}$ when assessed by staining, but showed similar viability characteristics as $H$. nuesslini when analyzed morphologically. Evaluation of spore viability by fluorescent staining correlated with morphological assessment, although fewer viable actinospores were usually detected microscopically. Polar filament discharge activity of morphologically intact actinospores did not significantly decrease until the third day of storage compared to freshly harvested samples. The results indicate that durability and reactivity trends during storage of actinospores differ among myxozoan species.
\end{abstract}

The period of time between release of actinospores from the invertebrate host and transmission to their respective fish host is a pivotal period in the life cycle of myxozoans. These delicate waterborne stages have evolved to attach to surfaces of fish using extrudible filaments from polar capsules prior to release of the infective parasite germ, the sporoplasm. Being immotile and rather short-lived, the physiological adaptations that myxozoan actinospores rely on during transmission to fish hosts are thought to reflect a strategy of mass production rather than to invest in adaptations for durability. Actinospores are prone to predation, damage, physiological and osmotic stress, and in spite of all this have to retain their ability to quickly infect host fish for as long as possible.

Most contemporary studies on myxozoans and their actinospores have concerned descriptive or life-cycle related (e.g. Atkinson et al. 2007, Kaltner et al. 2007), molecular and morphological (e.g. Hallett et al. 2004, Eszterbauer et al. 2006, Holzer et al. 2006, Székely et al. 2007), as well as phylogenetic (e.g. Fiala 2006, Jimenez-Guri et al. 2007) aspects. Another focus in myxozoan research is to use infection experiments to gain information on behaviour, physiology and functional adaptations for host infection (e.g. Yokoyama and Urawa 1997, Yokoyama et al. 2006, Kallert et al. 2005a, 2007). While some data exist on the natural viability of these transmission stages, showing survival may range from a few days up to weeks (Markiw 1992, Yokoyama et al. 1993, Özer and Wootten 2002), great interest has been drawn by methods to eliminate actinospores from water bodies e.g. in aquaculture (e.g. Wagner et al. 2003, Hedrick et al. 2007).

The transmission success of myxozoan actinospores is crucially influenced by the integrity of their cellular components and the ability to attach to a suitable host organism. Besides physical durability, parameters which influence infectivity include a viable sporoplasm primary cell and function of the polar capsule discharge reaction for host attachment. Presumably, if the motile primary cell is damaged, host penetration will not take place even if the overall structure of the actinospore appears intact. This study investigates not only the longevity of actinospores after emission from the invertebrate (oligochaete) host, but especially emphasises their infectivity by testing their reactivity after ageing and storage. The aim was to see whether the ability of host recognition and attachment is still given in viable but aged actinospores. Moreover, a potential correlation between morphological diagnostic features of triactinomyxon spores and their viability is explored. Such data would provide new information for researchers working with actinospores in the course of physiological and behavioural studies as well as infection experiments.

\section{MATERIALS AND METHODS}

Parasite cultivation. For Myxobolus cerebralis Hofer, 1903 cultivation, infected Tubifex tubifex Müller cultures were obtained from our laboratory cycle. Henneguya nuesslini 
Schuberg et Schröder, 1905 and naïve 4-7 months old (3-6 $\mathrm{cm}$ long) parasite-free brook trout Salvelinus fontinalis (Mitchill) and brown trout Salmo trutta fario L. were collected from a local hatchery (Bavaria, Germany). Myxobolus pseudodispar Gorbunova, 1936 (18S rDNA GenBank accession number AF466654) came from our established laboratory cycle using self-reared myxozoan-free roach Rutilus rutilus L. The cultivation of all three myxozoan species is summarized in Kallert et al. (2007), with $H$. nuesslini maintenance further described in Kallert et al. (2005b). Myxospores were isolated by tissue homogenisation for $2-5 \mathrm{~min}$ and oligochaetes were infected by the addition of $0.5-2 \times 10^{6}$ myxospores to the cultures. Triactinomyxon spores were harvested by filtration using $20 \mu \mathrm{m}$ nylon mesh size. All fish were kept at $12-15^{\circ} \mathrm{C}$ under a constant flow of dechlorinated tap water and fed on conventional pellets or fish flakes. Oligochaetes were fed weekly using a mixture of frozen Artemia larvae, spray-dried Spirulina and frozen lettuce.

Experimental design. Spores less than $16 \mathrm{~h}$ old were harvested from infected oligochaete cultures, then concentrated to a volume of $3.5-4 \mathrm{ml}$ and pipetted into $5 \mathrm{ml}$ rolled-edge glasses. Spore aliquots were then used to measure viability and discharge rates on the same day (d 1). The remaining spores were kept in the open glasses at $4^{\circ} \mathrm{C}$ and $12^{\circ} \mathrm{C}$. Followup measurements were conducted with additional aliquots on d 2 and d 3. All measurements were conducted with actinospores from at least 3 different days' yields; replicates are given in the results.

Rainbow trout Oncorhynchus mykiss (Walbaum) mucus was prepared as previously described by Kallert et al. (2005a) Polar filament discharge rates were measured by a modification of the method described therein. Briefly, $9 \mu \mathrm{l}$ of buffered mucus $(1 \mathrm{mg} / \mathrm{ml}$ final concentration) or control substrate were added to $21 \mu \mathrm{l}$ buffered actinospore suspension on slides and covered with a cover slip $(20 \times 20 \mathrm{~mm})$ followed by mechanical stimulation $(3 \mathrm{~s} 50 \mathrm{~Hz}$, amplitude $0.5 \mathrm{~mm}$; calibration: PenScope PS40M10 Meilhaus Electronics, EasyScope software, USB Instruments). The discharge rate was determined by counting actinospores with at least one discharged polar filament, specimens visually dead or damaged were not included. Buffered deionized water served as control in all experiments. All media were adjusted to $\mathrm{pH} 7.5(5 \mathrm{mM}$ sodium phosphate buffer). Spore suspensions were stored at $12^{\circ} \mathrm{C}$ during experiments, test substrates were kept on ice. A blinded protocol was used by coding the test substrates.

Viability measurement. Morphological evaluation of actinospore viability was conducted under a stereomicroscope with phase contrast optics. Parameters for specimens judged as viable were a naturally condensed sporoplasm in the apical region of the style, intact polar capsules and the distinct phase contrast interference shift of the sporoplasm primary cell. Parameters indicating non-viable specimens included ruptured valve cells, visible cellular damage, dull grey appearance of the sporoplasm under phase contrast, its elongation (to about 2-3 times its original size), facile visibility of the secondary sporoplasm cells and dislocation of the sporoplasm downwards along the spore axis without any movement. Morphological data were always obtained with samples used during the discharge test. Spore viability was also assessed by the double-staining technique of Markiw (1992). Using fluores- cence microscopy, viable spores had a bright green sporoplasm resulting from staining by fluorescein diacetate (FDA), while when cell membrane integrity was impaired, nuclei stained red with propidium iodide (PI).

Statistical methods. Statistical analysis was performed using SPSS and StatistiXL software. Homogeneity of variance was controlled using the Levene Test procedure, normal distribution was controlled by the Shapiro-Wilk Test (threshold $P$ $<0.02$ ) and visually by detrended Normal Q-Q-plots. Where necessary, data were arcsine/square root-transformed to obtain approximately normally distributed data. In these cases, mean values and standard errors were calculated from the transformed data and were retransformed thereafter. For comparison of independent samples data, a multiple post-hoc test was used (Tukey HSD). As a nonparametric alternative, i.e. if normal distribution could not be established, the KruskalWallis Test was performed. Differences between dependent means (e.g. data from one species at different time-points from the same population) were tested for statistical significance by Repeated Measures ANOVA without data-transformation. When normal distribution of data was not given, the Friedman Test for average ranking comparison of related samples was applied.

\section{RESULTS}

On $\mathrm{d} 1$, the viability rate of all species was $>80 \%$ as determined by both methods, except for the morphological evaluation of $M$. cerebralis which showed $<80 \%$ intact specimens. For most $M$. cerebralis isolates, a higher mean percentage (up to $19.7 \%$ difference on d 1) of spores were assessed as viable with FDA/PI staining than with morphological parameters (Fig. 1A and B left, $91.4 \%$ vs. $71.7 \%, P=0.12$ on $\mathrm{d} 1)$. However, the viability rate obtained by both methods after storage at $12^{\circ} \mathrm{C}$ was the same on d $3(0.44 \%$ difference $)$. On $d 2$, after storage at $12^{\circ} \mathrm{C}$, only $43.0 \%$ of spores were viable $(P=$ 0.04 vs. $\mathrm{d} 1$, morphology method), whereas storage at $4^{\circ} \mathrm{C}$ resulted in a mean of $55.9 \%$ survivors (Fig. 1A left). The relative decrease difference of $12.9 \%$ between storage at these temperatures was even higher by the staining method $(20 \%)$. After the $3 \mathrm{~d}$ period and storage at $12^{\circ} \mathrm{C}$, no more than $13.5 \%$ of $M$. cerebralis actinospores were viable according to FDA/PI staining ( $P$ $<0.001$ on $\mathrm{d} 1$ vs. d 3). For both methods, a greater decrease in viability was seen after storage at $12^{\circ} \mathrm{C}$ than at $4{ }^{\circ} \mathrm{C}(17.5 \%$ and $29.4 \%$ viability decrease difference between the two storage temperatures determined by the morphological and the FDA/PI-staining method respectively; $P=0.016$ and $0.13,4^{\circ} \mathrm{C}$ vs. $12^{\circ} \mathrm{C}$ on $\mathrm{d} 3$ for both methods, respectively).

Henneguya nuesslini actinospores almost retained their initial viability when stored at $4{ }^{\circ} \mathrm{C}$ (Fig. 1B, middle, $P=0.41$, d 1 vs. d 3, morphology method). On d 2 at $12^{\circ} \mathrm{C}$, the viability rate determined by staining exceeded the initial level slightly (Fig. 1A, middle), an inconsistency due to methodical bias. A greater decrease was observed using FDA/PI staining at $12^{\circ} \mathrm{C}$ than at $4^{\circ} \mathrm{C}$ on $\mathrm{d} 3(P=0.05)$ by independent sample analysis, 

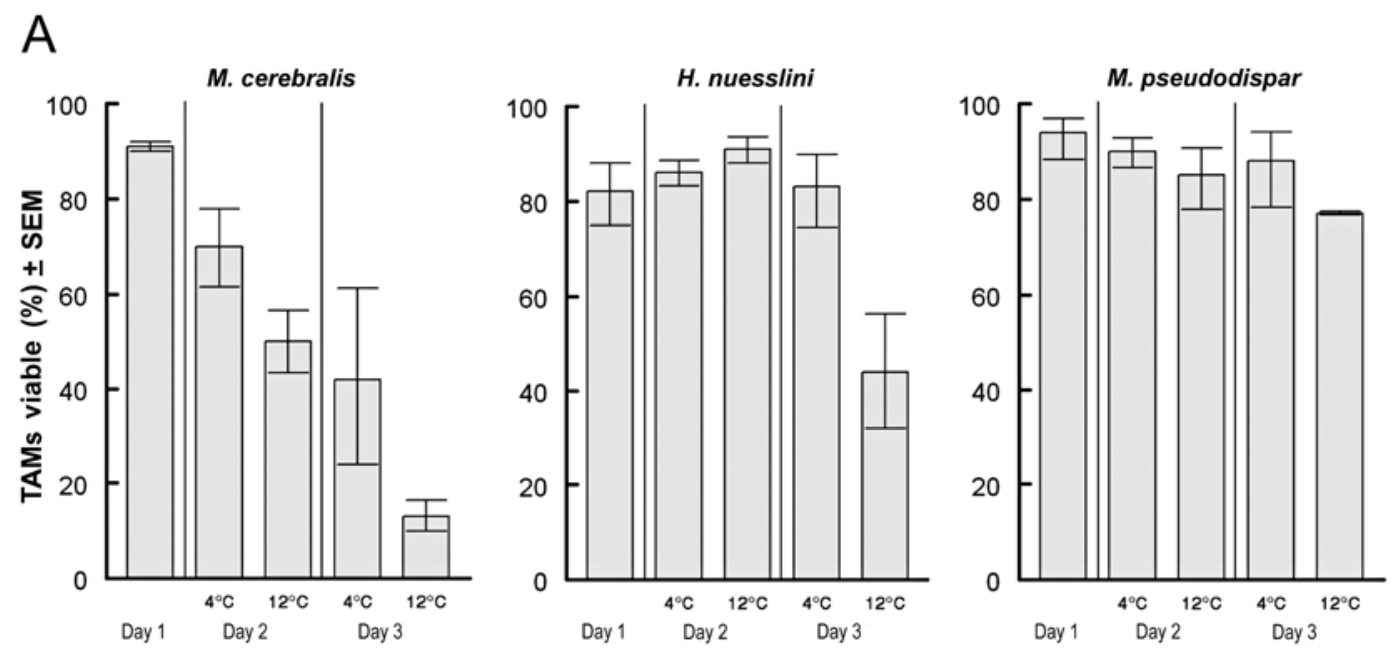

B
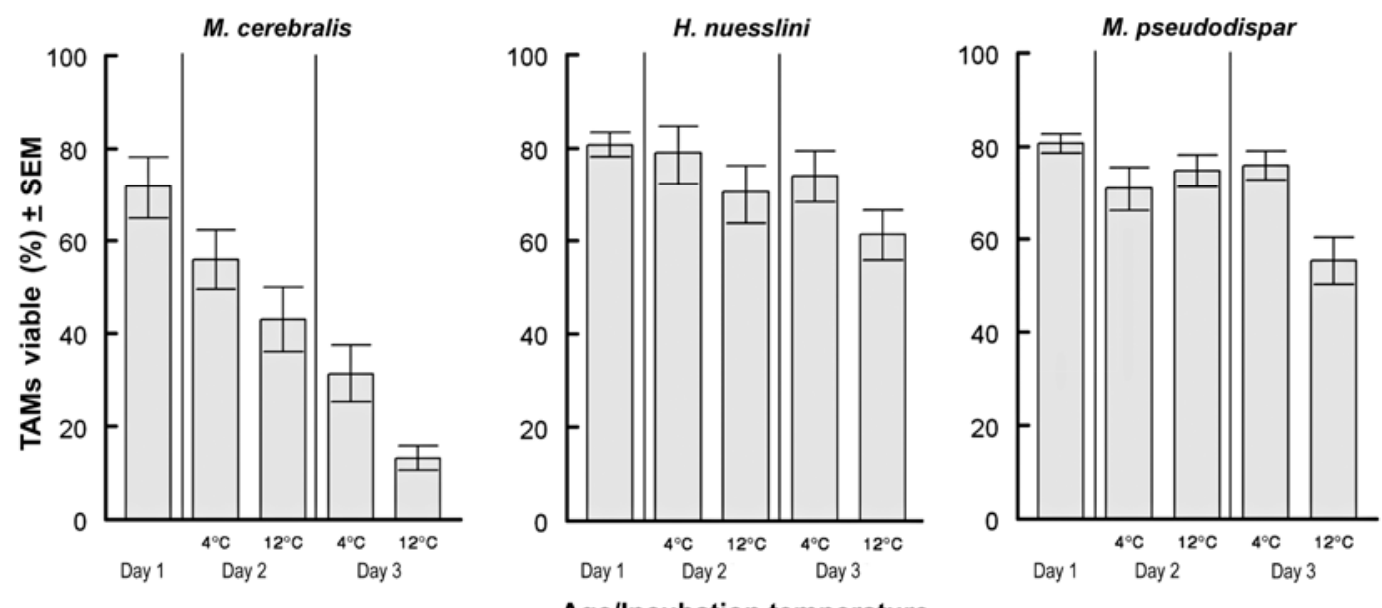

Fig. 1. Percent viable actinospores of the three myxozoan species determined by (A) FDA/PI double-staining (fluorescence microscopy) and (B) morphological characters (light microscopy) on the date of harvest (day 1) and after storage at $4^{\circ} \mathrm{C}$ and $12^{\circ} \mathrm{C}$ on two subsequent days (days 2 and 3). Total range of number of specimens per day/temperature: (A): 30-42 (Myxobolus cerebralis), 34-67 (Henneguya nuesslini), 65-86 (Myxobolus pseudodispar), all combinations per species tested in 3 replicates; (B): 135-157 (Myxobolus cerebralis), 84-160 (Henneguya nuesslini), 87-137 (Myxobolus pseudodispar), all combinations per species tested in 6 replicates. Abbreviations: SEM - standard error of the mean; TAMs - triactinomyxon spores.

however, the overall decrease was not significantly different between the temperatures in the pairwise sample analysis $(P=0.39, \mathrm{FDA} / \mathrm{PI}$-staining method, $P=$ 0.41 , morphology method, d 1 vs. $d 3$ at $12^{\circ} \mathrm{C}$ ). By all means, the viability loss measured by the staining method could not be confirmed in this size by morphological judgment (Fig. 1A and B, middle). With the latter, the estimated viability rate of $H$. nuesslini actinospores was still $60.5 \%$ on $\mathrm{d} 3$ after storage at $12^{\circ} \mathrm{C}$.

The greatest resistance against storage and ageing was found in M. pseudodispar (Fig. 1, right). This species showed the greatest $d 1$ viability rate of $94.1 \%$, by FDA/PI staining (but only $80.6 \%$ by morphology). On d 3 of storage at $12^{\circ} \mathrm{C}, 77.5 \%$ of the actinospores were not impaired in M. pseudodispar, which is a loss of only $16.6 \%$ compared to $\mathrm{d} 1$ (FDA/PI staining). In contrast, with a mean loss of $25.4 \%$ obtained by morphological estimation, a discrepancy between the two methods became obvious $(P=0.02)$. Both evaluation techniques showed no significant viability decrease at $4^{\circ} \mathrm{C}(P=$ 0.99 and 0.15 , d 1 vs. d 3, FDA-staining and morphology method respectively).

The use of morphology to judge the viability status of all species' actinospores gave up to $20 \%$ lower survival rates than the staining method, with the exception of $H$. nuesslini, where d 1 estimates were the same by both methods (Fig. 1A and B, middle). Morphological assessment showed higher values on d 3 after storage at $12^{\circ} \mathrm{C}(60.5 \%$ compared to $44.1 \%$ by FDA/PI staining). Myxobolus cerebralis was less robust than both other species even at $4^{\circ} \mathrm{C}(P<0.001$, vs. $H$. nuesslini, $P$ $<0.001$, vs. M. pseudodispar on d 3). Myxobolus pseu- 

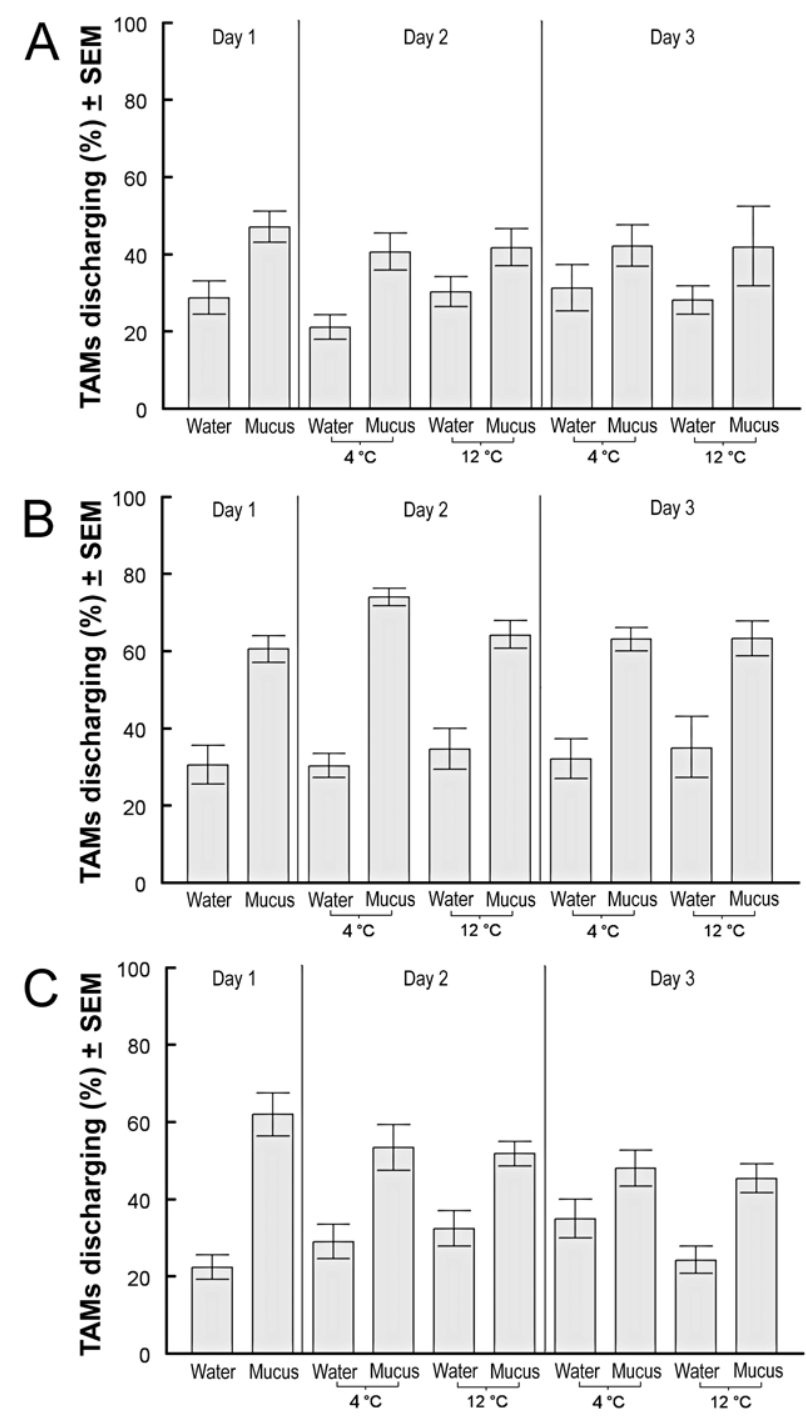

Substrate/Incubation temperature

Fig. 2. Percent discharged actinospores of the three myxozoan species: (A) Myxobolus cerebralis, (B) Henneguya nuesslini and (C) Myxobolus pseudodispar on the date of harvest (day 1) and after storage at $4{ }^{\circ} \mathrm{C}$ and $12^{\circ} \mathrm{C}$ on two subsequent days (days 2 and 3). Stimulating agent consisted of trout mucus homogenate $(1 \mathrm{mg} / \mathrm{ml}$ final concentration), water served as control substrate. Total range of number of specimens per day/temperature: 55-233 (Myxobolus cerebralis), 109-279 (Henneguya nuesslini), 119-224 (Myxobolus pseudodispar); all combinations per species tested in 12 replicates. Abbreviations: SEM - standard error of the mean; TAMs - triactinomyxon spores.

dodispar showed a greater durability than $H$. nuesslini by staining $\left(P=0.05, \mathrm{~d} 3\right.$ at $\left.12^{\circ} \mathrm{C}\right)$ but the viability of both species was the same when morphology was used (Fig. 1B, middle and right). The mean decrease in $M$. pseudodispar viability was $25 \%$ from d 1 to $\mathrm{d} 3$ (at $12^{\circ} \mathrm{C}$ ) by morphology, but $8.13 \%$ by staining. Hence, the relative differences in viability between storage days and temperatures obtained by the staining method could be reproduced adequately using morphological parame- ters, whereas the absolute bias in viability percentages between the two methods was obvious though not significant in many cases (e.g. $P=0.30$ for $M$. cerebralis on $\mathrm{d} 2$ after storage at $4^{\circ} \mathrm{C}$ ).

The discharge activity of all species was unexpectedly constant over the course of the trial (Fig. 2). In $M$. cerebralis, the mean difference between mucus-induced reaction and spontaneous discharge was only $18.5 \%$ at $4^{\circ} \mathrm{C}$, whereas at $12^{\circ} \mathrm{C}$ there was greater variation between replicates on d 3 (Fig. 2A). Curiously, the discharge rate of $H$. nuesslini significantly increased from $62.0 \%$ to $74.0 \%$ on $\mathrm{d} 2$ after storage at $4^{\circ} \mathrm{C}(P=0.002$, Fig. 2B). In this species, the relation of mucus-induced discharge and spontaneous discharge to non-discharging specimens remained constant over time $(P=0.99, \mathrm{~d} 1$ vs. d 3 after storage at $4^{\circ} \mathrm{C}$ ). Spontaneous discharge to control-substrate rose from $22.3 \%$ to $34.9 \%$ in $M$. pseudodispar actinospores only after storage at $4{ }^{\circ} \mathrm{C}$ (Fig. $2 \mathrm{C}$ ). In this species, the difference between reacting and non-reacting specimens varied the greatest. At beginning of the experiment $62.1 \%$ of actinospores discharged as response to the addition of mucus, yet only $45.4 \%$ discharged following $3 \mathrm{~d}$ storage at $12^{\circ} \mathrm{C}(P=$ $0.012)$.

\section{DISCUSSION}

The intention of this study was to evaluate the infectivity status of a given sample of actinospores and hence improve preparation of parasite samples for laboratory handling e.g. for infection experiments and also to confer data to epidemiological discussion. Data on actinospore viability are rather inconsistent. The longest survival of actinospores was found by Yokoyama et al. (1993), who found echinactinomyxon, raabeia and aurantiactinomyxon types to be viable for $2-4$ weeks. The latter authors defined viability as the period of time to full cellular disintegration, i.e. the loss of the entire sporoplasm. When Özer and Wootten (2002) addressed the temperature-dependent longevity of 5 types of actinospores by FDA/PI staining, viability of all types decreased with increasing temperature and ranged from $6-$ 7 days at $4^{\circ} \mathrm{C}$ to 4 days at $22^{\circ} \mathrm{C}$. Investigations on Myxobolus cerebralis actinospore longevity by Markiw (1992) showed a viability of $3-4 \mathrm{~d}$ at $12.5^{\circ} \mathrm{C}$, and shorter survival periods at higher temperatures with a decreased ability to infect trout. At $7^{\circ} \mathrm{C}$, over $80 \%$ were viable on day 4 and even $10 \%$ on day 7 . On day $4,50 \%$ were viable at higher temperatures, whereas the results from infection experiments with those actinospores (at a dose of 10,000 spores per fish) showed no infection. This indicates that staining may therefore falsely denote "viable" spores even when the spores already lost infectivity, which highlights the importance of using alternative methods such as discharge potency assessment.

In the current study, to avoid an additional ageingeffect, both viability-testing methods were not conducted simultaneously, so separate isolates from differ- 
ent harvesting days were used. The subjectivity of the morphological estimation method is obvious and theoretically results in a higher inherent error level. As the conduction requires certain experience of the investigator to be reproducible, six instead of only three replicates of trials were conducted. Morphology may also give a wrong impression by excluding those actinospores with physically damaged valves or an 'unsightly' sporoplasm that may actually represent a fully intact and infective entity. This may explain the lower viability rate we observed with Myxobolus pseudodispar by morphology than by the staining method. The FDA/PI double-staining method originally was developed by Mátyus et al. (1983) for sperm cell viability assessment. Wagner et al. (2003) managed to verify that PI-stained sporoplasms of $M$. cerebralis are indeed not infectious to susceptible fish any more. By this method, we observed an increase in polar filament discharge due to the $\mathrm{pH}$ shift (or the trace acetone from FDA dissolvent), rendering polar capsule cells non-viable due to propidium iodide influx. Therefore, presence of discharged polar capsules was excluded from the evaluation of actinospore viability. Empty actinospore shells were also not included in the study as their numbers did not significantly rise during the test period.

The frequently significant differences between the two viability-estimation methods may be explained by various difficulties in interpreting results from the staining technique. First of all, fully disintegrated specimens may not be stained any more, which may be hard to detect by fluorescence microscopy. On the other hand, the staining method may exaggerate the actual number of viable specimens to a certain degree as already shown for Giardia muris (Labatiuk et al. 1991). The fluorescence raised by FDA is achieved by cellular esterase activity, which may work even after cellular impairment. As a consequence, actinospores with intact cellular metabolism and membrane integrity may also be not infective due to physiological effects that are not detectable by staining methods. This may have been the reason for the 'increase' in viability rate measured for Henneguya nuesslini on $\mathrm{d} 2$ at $12^{\circ} \mathrm{C}$ by the staining technique, vividly showing the weakness of the method. Viable sporoplasm secondary cells do not reflect the viability status of the primary cell, which would explain the contradictory results by Markiw (1992), who demonstrated low to no infectivity of aged actinospores even though they were stained as viable. However, PI influx into the cell lumen is a definite indicator of cellular disintegration and thus signifies non-infectivity.

The actinospore isolates consisted of a population of specimens released at different points of time (although not older than $24 \mathrm{~h}$ ), rendering the exact release timepoint unacquainted. Although the true viability bias between the populations harvested on different dates may also be reflected in the data, it is unlikely that 3 harvests for staining could give a totally different pic- ture than 6 used for discharge/morphology carried out on adjacent days. The discharge-activity data were strictly obtained from specimens morphologically viable to avoid unwanted interfusion of data from parasites with different preconditions. The relatively low discharge rates of all species, but especially $M$. cerebralis, are explained by a consistently high number of rather quickly sporoplasm-emitting specimens that could not be included in the analysis. As all species used have shown a lack of host-specific discharge behaviour (see Kallert et al. 2005a, 2007), rainbow trout mucus was used as general chemo-stimulus. The number of intact spores evaluated during the discharge testing declined considerably until d 3 in all species. Specimens were either damaged or obviously disintegrated, so that only $24 \%$ (see Fig. 2, legend) of the initial total number of $M$. cerebralis actinospores per sample could be used for discharge analysis on the last day of the experiment.

The constancy in discharge rates observed in all species is explained by the fact that no morphologically impaired actinospores are included in these data. Those actinospores that visibly survived the storage conditions were still competent for attachment to a proportion as on $\mathrm{d} 1$ of the trials. Nevertheless, spontaneous discharge of $M$. pseudodispar increased after storage. Compared to $M$. cerebralis, the higher discharge rate of M. pseudodispar underlines its known inherent mechanical sensitivity already reported by Kallert et al. (2007). In this species, both discharge and sporoplasm (endospore) emission usually take place very quickly and can easily be stimulated with suitable fish mucus substrates as reported by the latter authors. This may reflect an adaptation to host transmission in standing water bodies, a typical environment for its most susceptible host, the roach. Differential durability at the two temperatures presumably reflects adaptation to the habitat of the host, at least for $M$. cerebralis and $M$. pseudodispar. Obviously, there seems to be no selective pressure on increased longevity for $M$. cerebralis. Besides, it may be an alternative strategy that those myxozoans with much less secondary sporoplasm cells (M. pseudodispar and $H$. nuesslini) invest rather into longevity than in number of infective entities, considering that additional secondary cells require more resources.

While spores accumulate in cultures, ageing may result in a growing proportion of non-infective actinospores, which may raise problems in infection trials when e.g. a dose-effect is under investigation. Such isolates cannot be looked at as a homogenous sample as their subsets may differ in viability and thus in infectivity. As a conclusion, researchers would have to apply tests as described herein to obtain data to conclude harvesting periods and storage conditions suitable for their respective myxozoan parasite's longevity. Another aspect that requires investigation in this context is the question whether the discharge activity and the sporoplasm motility of actinospores stored at very low tem- 
peratures for later use are affected considerably by such conditions. The question rises whether the observed temperature-related differences in infection prevalence may be explained partially by actinospore longevity and whether our data are relevant in the field at all. Baldwin et al. (2000) found a significant relation between water temperature and the percent of infected rainbow trout. But according to their results, prevalence was very low until $6^{\circ} \mathrm{C}$ were reached, while at $11^{\circ} \mathrm{C}$, numbers of infected fish rose to over $80 \%$. However, this effect may be due to an increase in production of actinospores as it contradicts our findings on the viability of $M$. cerebralis.

In conclusion, our results suggest that the longevity of myxozoan actinospores differs among species with temperature, probably in concordance to their respective host habitats and infective secondary cell number. Morphological parameters and spore discharge rates can be used to estimate the infective percentage of a given actinospore isolate e.g. for infection dose estimation in experimental infections.

Acknowledgements. Thanks are due to Daniel Grabner and Edit Eszterbauer for practical help and revision of the manuscript. Statistical advice was kindly provided by Martin Hofmann of the Mathematical Institute of The University of Würzburg. This study was carried out in the course of a research project funded by grant from the Deutsche Forschungsgemeinschaft (EL-174/2-1).

\section{REFERENCES}

ATKINSON S.D., HALLETT S.L., BARTHOLOMEW J.L. 2007: The life cycle of Chloromyxum auratum (Myxozoa) from goldfish, Carassius auratus (L.), involves an antonactinomyxon actinospore. J. Fish Dis. 30: 149-156.

BALDWIN T.J., VinCENT E.R., Silflow R.M., STANEK D. 2000 Myxobolus cerebralis infection in rainbow trout (Oncorhynchus mykiss) and brown trout (Salmo trutta) exposed under natural stream conditions. J. Vet. Diagn. Invest. 12: 312-321.

ESZTERBAUER E., MARTON S., RÁCZ O.Z., LETENYEI M., MOLNÁR K. 2006: Morphological and genetic differences among actinosporean stages of fish-parasitic myxosporeans (Myxozoa): difficulties of species identification. Syst. Parasitol. 65: $97-114$.

FIALA I. 2006: The phylogeny of Myxosporea (Myxozoa) based on small subunit ribosomal RNA gene analysis. Int. J. Parasitol. 36: 1521-1534.

Hallett S.L., AtKinson S.D., ERsÉus C., El-Matbouli M. 2004: Molecular methods clarify morphometric variation in triactinomyxon spores (Myxozoa) released from different oligochaete hosts. Syst. Parasitol. 57: 1-14.

Hedrick R.P., Petri B., MCDOWell T.S., MukKatiRA K., SEALEY L.J. 2007: Evaluation of doses of ultraviolet irradiation to inactivate waterborne actinospore stages of Myxobolus cerebralis. Dis. Aquat. Org. 74: 113-118.

Holzer A.S., SOMMERVILLE C., WoOTTEN R. 2006: Molecular identity, phylogeny and life cycle of Chloromyxum schurovi Shul'man \& Ieshko 2003. Parasitol. Res. 99: 90-96.

Jimenez-Guri E., PhilipPe H., OKamura B., Holland P.W. 2007: Buddenbrockia is a cnidarian worm. Science 6: 116118

KAllert D.M., El-Matbouli M., HaAs W. 2005a: Polar filament discharge of Myxobolus cerebralis actinospores is triggered by combined non-specific mechanical and chemical cues. Parasitology 131: 609-616.

Kallert D.M., EsZTerbauer E., El-Matbouli M., ERsÉus C., HAAS W. 2005b: The life cycle of Henneguya nuesslini Schuberg \& Schröder 1905 (Myxozoa) involves a triactinomyxontype actinospore. J. Fish Dis. 28: 71-79.
Kallert D.M., Ponader S., Eszterbauer E., El-Matbouli M., HAAS W. 2007: Myxozoan transmission via actinospores: new insights into mechanisms and adaptations for host invasion. Parasitology 30: 1741-1750.

Kaltner H., StipPl M., Knaus M., El-Matbouli M. 2007: Characterization of glycans in the developmental stages of Myxobolus cerebralis (Myxozoa), the causative agent of whirling disease. J. Fish Dis. 30: 637-647.

LABATIUK C.W., SCHAEFER 3RD F.W., FINCH G.R., BELOSEVIC M. 1991: Comparison of animal infectivity, excystation, and fluorogenic dye as measures of Giardia muris cyst inactivation by ozone. Appl. Environ. Microbiol. 57: 3187-3192.

MARKIW M.E. 1992: Experimentally induced whirling disease II. Determination of longevity of the infective triactinomyxon stage of Myxobolus cerebralis by vital staining. J. Aquat. Anim. Health 4: 44-47.

MÁtyus L., SZABÓ G. JR., ReSLI I., GÁSPÁR R. JR. 1983: Flow cytometric analysis of viability of mammalian sperm cells. Acta Biochim. Biophys. Acad. Sci. Hung. 18: 75.

ÖZER A., WOOTTEN R. 2002: Biological characteristics of some actinosporeans. J. Nat. Hist. 36: 2199-2209.

SzÉKely C., Hallett S.L., Al-Samman A., Dayoub A. 2007: First description of myxozoans from Syria: novel records of hexactinomyxon, triactinomyxon and endocapsa actinospore types. Dis. Aquat. Org. 28: 127-137.

WAGNER E.J., SMITH M., ARNDT R., ROBERTS D.W. 2003: Physical and chemical effects on viability of the Myxobolus cerebralis triactinomyxon. Dis. Aquat. Org. 53: 133-142.

YoKoYAma H., KIM H.J., URAWA S. 2006: Differences in host selection of two myxosporeans, Myxobolus arcticus and Thelohanellus hovorkai. J. Parasitol. 92: 725-729.

YoKoyAmA H., OGAWA K., WAKABAYASHI H. 1993: Some biological characteristics of actinosporeans from the oligochaete Branchiura sowerbyi. Dis. Aquat. Org. 17: 223-228.

YOKOYAMA H., URAWA S. 1997: Fluorescent labelling of actinospores for determining the portals of entry into fish. Dis. Aquat. Org. 30: 165-169. 